\title{
Epigenetic therapy with the histone methyltransferase EZH2 inhibitor 3-deazaneplanocin A inhibits the growth of cholangiocarcinoma cells
}

\author{
SHIGEKI NAKAGAWA ${ }^{1}$, YASUO SAKAMOTO ${ }^{1,2}$, HIROHISA OKABE ${ }^{1}$, HIROMITSU HAYASHI $^{1}$, \\ DAISUKE HASHIMOTO ${ }^{1}$, NAOMI YOKOYAMA ${ }^{1}$, RYUMA TOKUNAGA ${ }^{1}$, KEITA SAKAMOTO ${ }^{1}$, \\ HIDEYUKI KUROKI $^{1}$, KOSUKE MIMA ${ }^{1}$, TORU BEPPU ${ }^{1,2}$ and HIDEO BABA ${ }^{1}$ \\ ${ }^{1}$ Department of Gastroenterological Surgery, Graduate School of Life Sciences, Kumamoto University; \\ ${ }^{2}$ Department of Multidisciplinary Treatment for Gastroenterological Cancer, \\ Kumamoto University Hospital, Kumamoto 860-0811, Japan
}

Received October 2, 2013; Accepted November 25, 2013

DOI: $10.3892 /$ or.2013.2922

\begin{abstract}
Enhancer of zeste homolog 2 (EZH2) is involved in malignant transformation and the biological aggressiveness of several human malignancies. Growing evidence indicates that EZH2 may be an appropriate therapeutic target for malignancies, including cholangiocarcinoma. Recently, an S-adenosyl-L-homocysteine hydrolase inhibitor, 3-deazaneplanocin A (DZNep) was shown to deplete and inhibit EZH2. The aim of this study was to determine the effect of DZNep and the combination of gemcitabine and DZNep in cholangiocarcinoma cells. The effects of DZNep and its combination with gemcitabine were assessed in the cholangiocarcinoma cell lines RBE and TFK-1. DZNep depleted the cellular levels of EZH2 and inhibited the associated histone H3 lysine 27 trimethylation. DZNep treatment resulted in the inhibition of proliferation in the cholangiocarcinoma cell lines, and the combination of DZNep and gemcitabine showed synergistic inhibition of cell proliferation. DZNep induced apoptosis and G1 phase cell cycle arrest in cholangiocarcinoma cells, and the combination of DZNep and gemcitabine enhanced the induced apoptosis and G1 arrest when compared with gemcitabine alone. Inhibition of cell proliferation by DZNep was partially associated with upregulation of $\mathrm{p} 16^{\mathrm{INK} 4 \mathrm{a}}$ and $\mathrm{p} 17^{\mathrm{KIP} 1}$. The present study shows that DZNep inhibits cell proliferation by inducing G1 arrest and apoptosis. These results indicate that an epigenetic therapy that pharmacologically targets EZH2 via DZNep may constitute a novel approach for the treatment of cholangiocarcinoma.
\end{abstract}

Correspondence to: Professor Hideo Baba, Department of Gastroenterological Surgery, Graduate School of Life Sciences, Kumamoto University, 1-1-1 Chuo-ku Honjo, Kumamoto 860-0811, Japan

E-mail: hdobaba@kumamoto-u.ac.jp

Key words: EZH2, DZNep, cholangiocarcinoma, cell cycle

\section{Introduction}

Cholangiocarcinoma is a malignant tumor originating from the bile duct epithelium $(1,2)$. Complete surgical resection is currently the only curative treatment for patients with cholangiocarcinoma. However, due to difficulties in the early diagnosis and its high metastatic potential, most patients with cholangiocarcinoma have regional or distant metastasis at the time of clinical diagnosis (3-5). Few specific diagnostic or therapeutic tools are available because of the limited information on the molecular pathogenesis of cholangiocarcinoma. Therefore, new therapeutic targets are urgently needed.

Epigenetic gene silencing is an important mechanism that results in loss of gene expression and that mediates, along with genetic mutations, the initiation and progression of human cancer. Polycomb group proteins regulate and mediate epigenetic transcriptional silencing $(6,7)$. They are involved in the maintenance of embryonic and adult stem cells and in repression of key tumor-suppressor pathways, which may contribute to their oncogenic function (8). The enhancer of zeste homolog 2 (EZH2) is the catalytic subunit of the polycomb repressive complex 2 (PRC2), which also includes the suppressor of zeste 12 (SUZ12) protein and embryonic ectoderm development (EED) protein. EZH2 acts as a histone lysine methyltransferase that mediates trimethylation of lysine 27 of histone $\mathrm{H} 3$ (3mH3K27) to silence expression of PRC2 target genes involved in lineage differentiation $(9,10)$. $\mathrm{EZH} 2$ is overexpressed in a variety of malignancies including prostate cancer, breast cancer, melanoma, uterine cancer, gastric cancer and renal cell cancer. EZH2 expression levels are correlated with aggressiveness, metastasis and a poor patient prognosis in most of these cancers (11-15). EZH2 is barely expressed in normal tissues of various types (16).

More recently, we found that cholangiocarcinoma also overexpresses EZH2 and that high expression of EZH2 is correlated with poor patient prognosis (17). Furthermore, an activating mutation in EZH2 has been identified in a subset of B-cell lymphomas (18). Overexpression of EZH2 enhances aggressiveness in prostatic cancer cells (19) and produces a 
neoplastic phenotype characterized by independent growth and cell invasion in immortalized mammary epithelial cells and bronchial epithelial cells $(13,20)$. Conversely, depletion of EZH2 results in reduced proliferation, increased apoptosis, and inhibition of tumorigenicity in cancer cells $(12,19,21,22)$ including cholangiocarcinoma cells (17). These findings indicate that EZH2 may be an appropriate therapeutic target for various types of cancers.

A cyclopentenyl analog of 3-deazaadenosine, 3-deazaneplanocin A (DZNep), inhibits the activity of S-adenosyl-L-homocysteine (AdoHcy) hydrolase, the enzyme responsible for the reversible hydrolysis of AdoHcy to adenosine and homocysteine (23). This inhibition results in the intracellular accumulation of AdoHcy, which leads to inhibition of S-adenosyl-L-methionine-dependent lysine methyltransferase activity. Presently, DZNep was shown to reduce levels of the PRC2 complex, including EZH2, in breast cancer cells and cause concomitant loss of 3mH3K27 and repression of epigenetically silenced target genes (24). Moreover, DZNep was found to inhibit proliferation and promote apoptosis in several types of cancer cells (24-29), and the synergistic interaction of DZNep and gemcitabine enhanced the inhibition of cell proliferation and apoptosis in pancreatic cancer cells (30).

However, data on the activity of DZNep in cholangiocarcinoma cells are scarce. In the present study, we demonstrated the effects of DZNep alone and in combination with gemcitabine on cholangiocarcinoma cells.

\section{Materials and methods}

Cell lines and chemicals. The cholangiocarcinoma cell lines RBE and TFK-1 were purchased from RIKEN Bioresource Center (Ibaraki, Japan). RBE and TFK-1 cell lines were cultured in RPMI-1640 (Invitrogen, Tokyo, Japan) containing $10 \%$ fetal bovine serum (FBS). All cultures were maintained in a $5 \% \mathrm{CO}_{2}$ air-humidified atmosphere at $37^{\circ} \mathrm{C}$. DZNep and gemcitabine were provided by Cayman Chemical Japan and Eli Lilly Japan, respectively.

Cell growth assay. Cells were seeded in a 96-well plate at a density of 5000 cells per well and treated with or without DZNep $(0.5 \mu \mathrm{M})$ or gemcitabine $(30 \mathrm{nM})$ or the combination. Viable cholangiocarcinoma cell numbers were measured with the Cell Counting Kit-8 (CCK-8) containing 2-(2-methoxy-4nitrophenyl)-3-(4-nitrophenyl)-5-(2,4-disulfophenyl)-2H-tetrazolium (WST-8) (Dojin Laboratories, Kumamoto, Japan) for 24,48 and $72 \mathrm{~h}$, according to the manufacturer's instructions. OD 450 was measured using an automatic microplate reader (Molecular Devices, Osaka, Japan). Each experiment was performed in triplicate.

Flow cytometric analysis of cell cycle distribution and detection of apoptosis. RBE and TFK-1 cells were seeded in a 12-well plate. After $72 \mathrm{~h}$ of treatment with or without DZNep $(0.5 \mathrm{nM})$ or gemcitabine $(30 \mathrm{nM})$ or the combination, cells were trypsinized, adjusted to $5 \times 10 \% / \mathrm{ml}$, and fixed in $70 \%$ ethanol overnight at $-20^{\circ} \mathrm{C}$. Subsequently, cells were pelleted and resuspended in phosphate-buffered saline containing $1 \mu \mathrm{g} / \mathrm{ml}$ RNase A (Sigma, Tokyo, Japan) and $100 \mu \mathrm{g} / \mathrm{ml}$ propidium iodide (PI) (Sigma). Cell cycle analyses were performed using a FACS

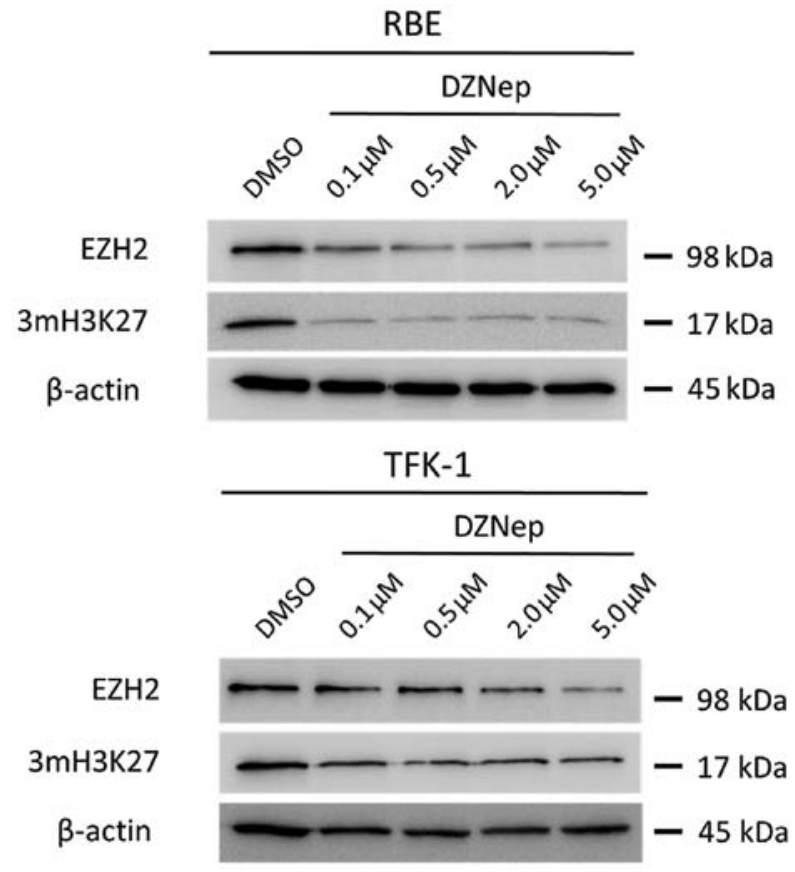

Figure 1. Western blot analysis of the RBE and TFK-1 cholangiocarcinoma cell lines. Cell lysates were collected $72 \mathrm{~h}$ after treatment with DZNep. Lysates were subjected to western blot analysis. Representative western blots of EZH2 and 3mH3K27; $\beta$-actin acted as a loading control.

Aria II (BD Biosciences, Tokyo Japan). The distribution of cells in different cell cycle phases was calculated using FlowJo software (Tomy Digital Biology Co., Ltd., Tokyo, Japan). Phosphatidylserine externalization was detected by Annexin V staining (Millipore, Tokyo, Japan) following the manufacturer's instructions. Annexin V-positive and PI-negative cells were detected as early apoptotic cells.

Statistical analysis. Statistical analysis was performed using the JMP program (SAS Institute, Cary, NC, USA). Quantitative data are expressed as means $\pm \mathrm{SD}$, unless otherwise stated. The $\chi^{2}$ test was used to analyze the relationship between categorical variables. For all statistical analyses, the level of significance was set at 0.05 .

\section{Results}

DZNep reduces EZH 2 expression and demethylated $H 3 K 27$ in cholangiocarcinoma cells. The expression of EZH2 was studied at the protein level in untreated RBE and TFK-1 cells and in cells treated with 0.1-5 $\mu \mathrm{M}$ DZNep. As shown in Fig. 1, DZNep reduced the expression of EZH2 in a dose-dependent manner. In addition, we investigated the expression of the $3 \mathrm{mH} 3 \mathrm{~K} 27$ protein, which was also reduced by DZNep in a dose-dependent manner in both cell lines.

DZNep inhibits the growth of cholangiocarcinoma cells and interacts synergistically with gemcitabine. We assessed the effect of DZNep-mediated EZH2 repression on the growth of RBE and TFK-1 cholangiocarcinoma cells (Fig. 2). The cell growth assay demonstrated that $0.5 \mu \mathrm{M}$ DZNep caused significantly inhibited proliferation of cholangiocarcinoma cells. As compared with control cells on day 3, DZNep reduced the 

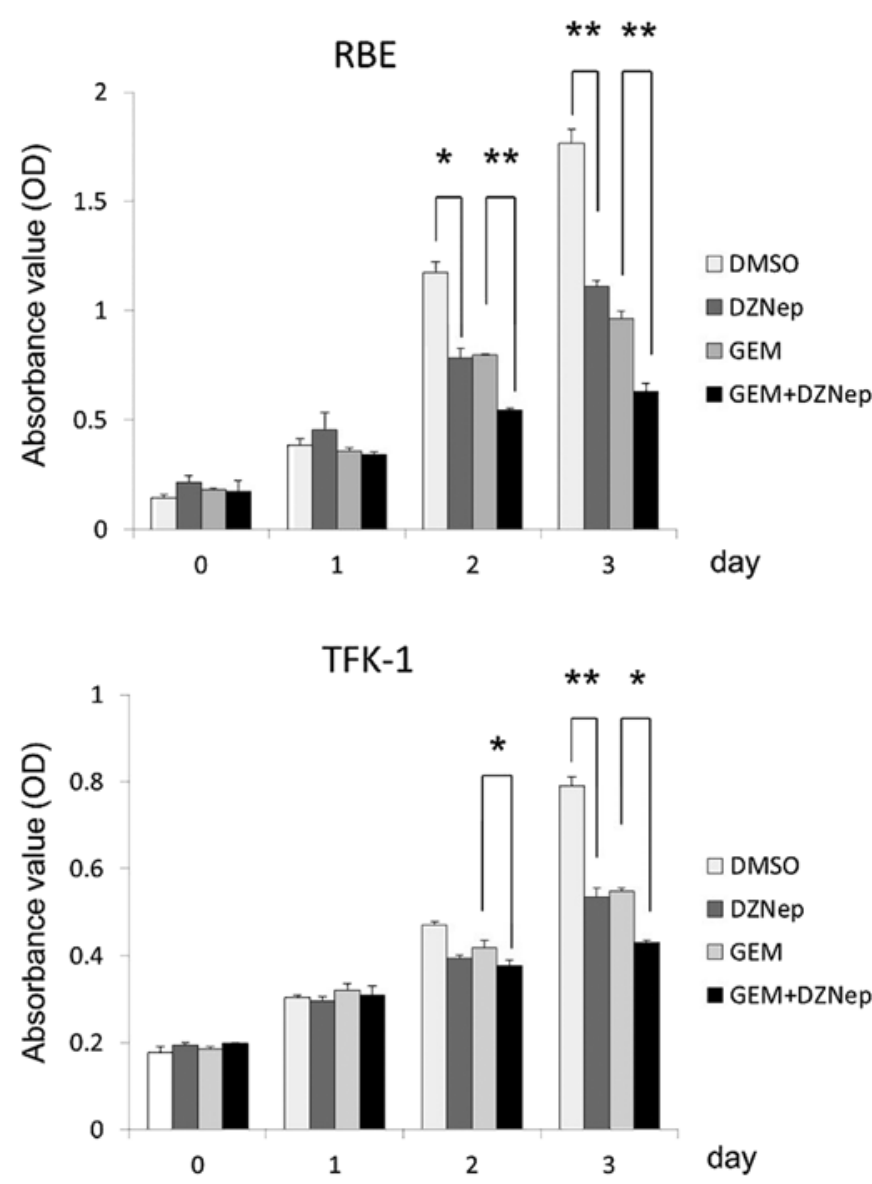

Figure 2. Inhibition of cell proliferation of the RBE and TFK-1 cholangiocarcinoma cell lines and pharmacological interaction of DZNep and gemcitabine. Experiments were performed in triplicate. Standard deviations are indicated. ${ }^{*} \mathrm{p}<0.05,{ }^{* *} \mathrm{p}<0.01$.

growth of RBE and TFK-1 cells to 67.0 and $67.6 \%$, respectively. Similarly, $30 \mathrm{nM}$ gemcitabine also significantly inhibited cell proliferation to 58.4 and $69.5 \%$ (in RBE and TFK-1 cells, respectively) as compared with the control cells on day 3 . The combination of $0.5 \mu \mathrm{M}$ DZNep and $30 \mathrm{nM}$ gemcitabine enhanced the antiproliferative activity of gemcitabine. The combination of DZNep and gemcitabine reduced the proliferation of RBE and TFK-1 cells to 61.2 and $78.6 \%$ compared with gemcitabine alone, and to 35.7 and $53.1 \%$ compared with the control cells (Fig. 2).

DZNep induces cell cycle arrest and the combination of DZNep and gemcitabine enhances cell cycle arrest. We used flow cytometry to determine whether the reduction in proliferation was due to cell cycle arrest or apoptosis in the two cholangiocarcinoma cell lines. DZNep alone and in combination with gemcitabine affected the cell cycle of cholangiocarcinoma cells (Fig. 3). In particular, DZNep increased the percentage of RBE and TFK-1 cells in the G0/G1 phase from 46.5 to $50.2 \%$ and from 49.1 to $59.2 \%$, respectively $(\mathrm{p}<0.05)$. Gemcitabine alone reduced the number of cells in the $\mathrm{G} 0 / \mathrm{G} 1$ phase to 28.3 and $36.1 \%$, respectively $(\mathrm{p}<0.05)$. The combination of DZNep and gemcitabine significantly increased the percentage of RBE and TFK-1 cells in the G0/G1 phase compared with gemcitabine alone (from 28.3 to $60.2 \%$
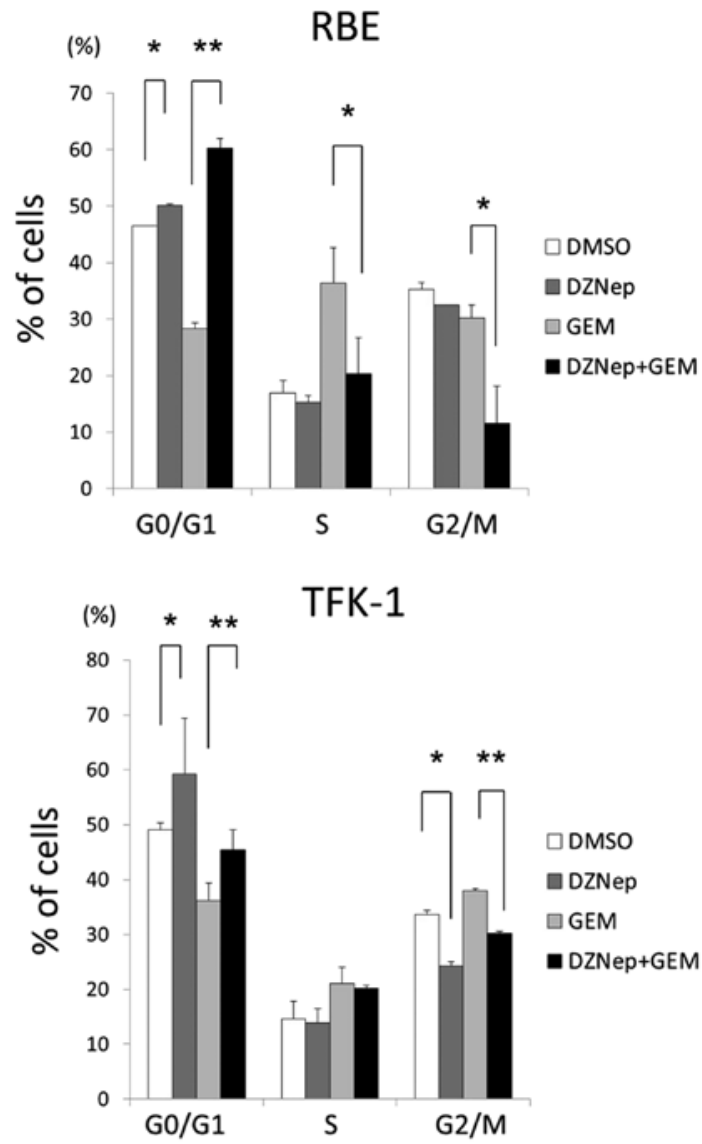

Figure 3. Effect of DZNep and gemcitabine on cell cycle distribution in the RBE and TFK-1 cholangiocarcinoma cell lines. Cells were treated with $0.5 \mu \mathrm{M}$ DZNep and $30 \mathrm{nM}$ gemcitabine and in combination. After $72 \mathrm{~h}$, the percentage of cells in each cell cycle phase was measured using a FACS flow cytometer. Experiments were performed in triplicate. Standard deviations are indicated. ${ }^{*} \mathrm{p}<0.05,{ }^{* *} \mathrm{p}<0.01$.

and from 36.1 to $45.4 \%$, respectively). Additionally, DZNep reduced the percentage of cells in the $\mathrm{S}$ and $\mathrm{G} 2 / \mathrm{M}$ phases, and the combination of DZNep and gemcitabine significantly reduced the percentage of cells in the $\mathrm{S}$ and G2/M phases compared with gemcitabine alone.

DZNep induces cell apoptosis and the combination of DZNep and gemcitabine enhances apoptosis. Flow cytometry using Annexin V and PI staining, and analysis of the sub-G1 region demonstrated that DZNep or gemcitabine alone significantly enhanced apoptosis when compared with the control cells (Fig. 4). Treatment with $0.5 \mu \mathrm{M}$ DZNep increased apoptosis 2 -fold, and treatment with $30 \mathrm{nM}$ gemcitabine resulted in $\sim 5$-fold increase in apoptosis. Furthermore, the combination of DZNep and gemcitabine significantly increased the number of apoptotic cells when compared with either agent alone ( $\sim 5$-fold and 2 -fold increases in the RBE and TFK-1 cells, respectively). We also investigated expression of cleaved caspase-3 and cleaved polyADP ribose polymerase (PARP) as markers of apoptosis to confirm the apoptotic effect of the combination of DZNep and gemcitabine. A slight increase in these proteins was noted followed treatment with DZNep alone, but the combination of DZNep and gemcitabine resulted in a significant increase in apoptotic proteins in the 
RBE
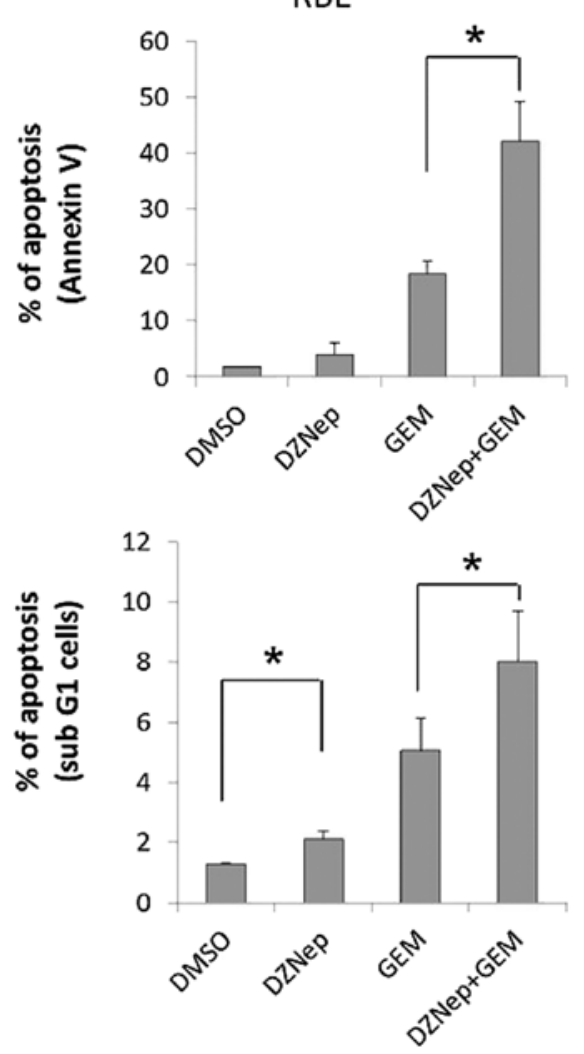

TFK-1
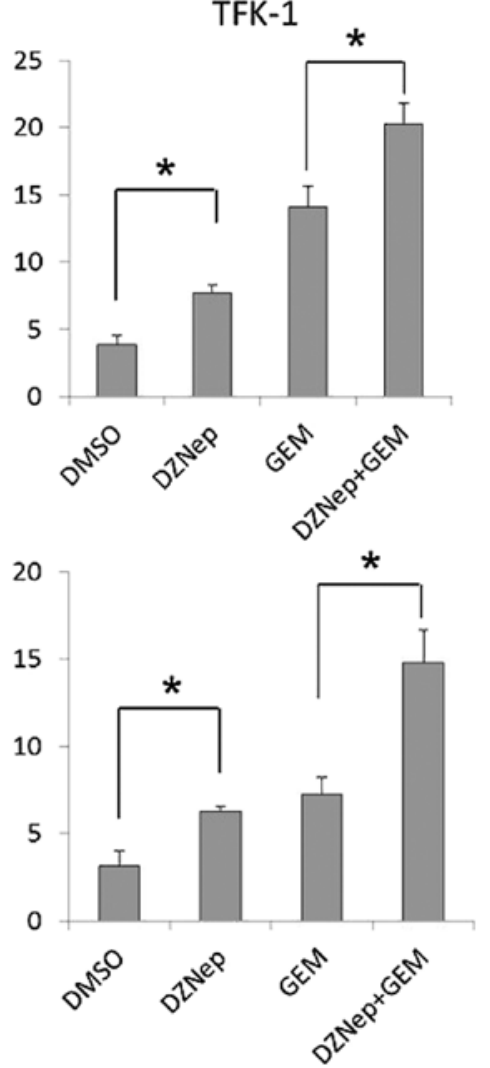

Figure 4. Analysis of the apoptosis of the RBE and TFK-1 cholangiocarcinoma cell lines using flow cytometry with Annexin V and PI staining, and determination of sub-G1 cells. Cells were treated with $0.5 \mu \mathrm{M}$ DZNep and $30 \mathrm{nM}$ gemcitabine or the combination. After $72 \mathrm{~h}$, the percentage of cells in the apoptotic fraction was measured using a FACS flow cytometer. Experiments were performed in triplicate. Standard deviations are indicated. ${ }^{*} \mathrm{p}<0.05,{ }^{* *} \mathrm{p}<0.01$.

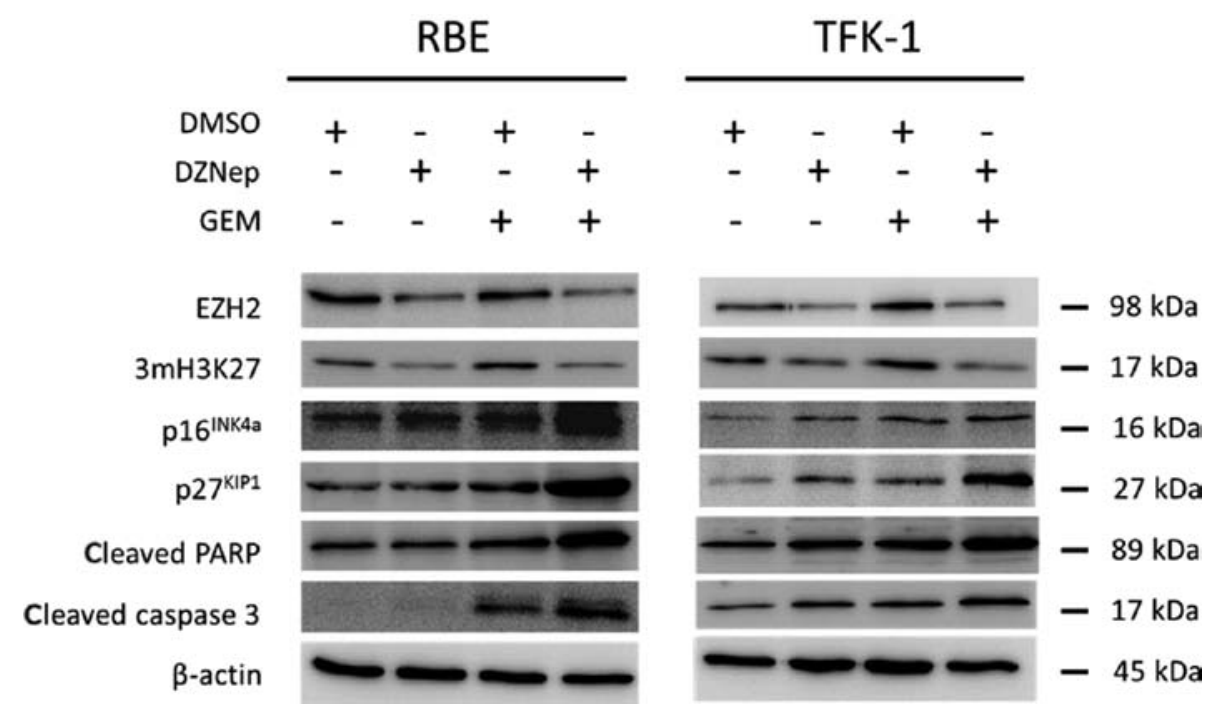

Figure 5. Western blot analysis of the RBE and TFK-1 cholangiocarcinoma cell lines. Cell lysates were collected $72 \mathrm{~h}$ after treatment with $0.5 \mu \mathrm{M}$ DZNep and $30 \mathrm{nM}$ gemcitabine or the combination. Lysates were then subjected to western blot analysis. Representative western blots of EZH2, 3mH3K27, p16 ${ }^{\mathrm{INK} 4 \mathrm{a}}$, p2 $7^{\mathrm{KIP} 1}$, cleaved PARP and cleaved caspase- $3 ; \beta$-actin acted as a loading control.

RBE and TFK-1 cells (Fig. 5). These results confirmed the flow cytometric analysis.

DZNep depletes EZH2 and $3 m H 3 K 27$ and increases p16 ${ }^{I N K 4 a}$ and $p 27^{K I P 1}$ in cholangiocarcinoma cells and the combination of DZNep and gemcitabine enhances these effects. DZNep reduced the expression of EZH2 protein and 3mH3K27 in cholangiocarcinoma cell lines (Fig. 5). The combination of DZNep and gemcitabine also reduced the expression of EZH2 and $3 \mathrm{mH} 3 \mathrm{~K} 27$ when compared with gemcitabine alone. We determined the effect of DZNep on EZH2 target genes such as $\mathrm{p} 16^{\mathrm{INK} 4 \mathrm{a}}$ and $\mathrm{p} 27^{\mathrm{KIP} 1}$. Expression of $\mathrm{p} 16^{\mathrm{INK} 4 \mathrm{a}}$ and $\mathrm{p} 27^{\mathrm{KIP} 1}$ 
was increased by DZNep. The combination of DZNep and gemcitabine enhanced the increase in expression of $\mathrm{p} 16^{\mathrm{INK} 4 \mathrm{a}}$ and $\mathrm{p} 27^{\mathrm{KIP} 1}$.

\section{Discussion}

The present study demonstrated that the combination of the EZH2 inhibitor DZNep and the cytotoxic compound gemcitabine exhibited strong synergistic effects on the cholangiocarcinoma cell lines. EZH2 has a master regulatory role in the fate of native embryogenic cells (31), as well as in cancer development via methylation-mediated repression of the transcription of several genes $(32,33)$. Overexpression of EZH2 is a marker of advanced and metastatic disease in many solid tumors, including cholangiocarcinoma $(12,13,34)$. EZH2 is crucial for regulating the cell cycle by repressing several tumor-suppressor genes such as $\mathrm{p} 16^{\mathrm{INK} 4 \mathrm{a}}, \mathrm{p} 27^{\mathrm{KIP1}}$ and RUNX3, and by mediating the pRb pathway. In addition, EZH2 regulates E2F1-dependent apoptosis directly in cancer cells, through modulation of Bim expression.

Our previous study on RBE and TFK-1 cells showed that suppression of EZH2 expression by RNA interference with siRNA targeting EZH2 markedly inhibited cellular proliferation in vitro, and drastically induced both cell cycle arrest and apoptosis $(17,35)$. Knockdown of EZH2 by siRNA increased expression of $p 16^{I N K 4 a}$ and $p 27^{K I P I}$, which are considered to be the targets of EZH2 (17). According to other research, transfection of shEZH2 construct cells sensitized MIA-PaCa-2 and Pac04.02 cells to doxorubicin and gemcitabine in pancreatic cancer (21), suggesting that the combination of EZH2 inhibitors and gemcitabine might overcome the intrinsic chemoresistance of cholangiocarcinoma. To the best of our knowledge, this is the first study evaluating the pharmacological interaction of the small-molecule EZH2 inhibitor DZNep with gemcitabine in cholangiocarcinoma cells.

In the cholangiocarcinoma cell lines, we observed a significant reduction of both EZH2 and 3mH3K27 expression in a dose-dependent manner. Analyses of the cell cycle distribution and apoptosis indicated that the growth suppression by DZNep was associated with G1 cell cycle arrest and increased apoptosis in cholangiocarcinoma cells. This conclusion is consistent with the findings from acute myeloid leukemia (AML) cells treated with DZNep (27). Knockdown of EZH2 by siRNA has also been shown to induce G1 cell cycle arrest and to increase apoptosis in cholangiocarcinoma cells and other types of carcinoma cells (36). DZNep induced accumulation of $\mathrm{p} 16^{\mathrm{INK} 4 \mathrm{a}}$ and $\mathrm{p} 27^{\mathrm{KIP} 1}$ in RBE and TFK-1 cells in the present study, and this may have resulted in G1 arrest and increased apoptosis. An association between either $\mathrm{p} 16^{\mathrm{INK} 4 \mathrm{a}}$ or $\mathrm{p} 27^{\mathrm{KIP} 1}$ accumulation and G1 cell cycle arrest and apoptosis has been shown in various types of cells $(37,38)$. Fiskus et al reported that DZNep treatment induced p16 $6^{\mathrm{INK} 4 \mathrm{a}}, \mathrm{p} 21^{\mathrm{CIP} 1}, \mathrm{p} 27^{\mathrm{KIP} 1}$ and FBXO32 while reducing cyclin E and HOXA9 levels in human AML cells (27). Taken together, these results indicate that growth suppression by DZNep is associated with G1 phase arrest and apoptosis in cholangiocarcinoma cells, partly via $\mathrm{p} 16^{\mathrm{INK} 4 \mathrm{a}}$ and p2 $7^{\mathrm{KIP1}}$ accumulation.

The Advanced Biliary Cancer (ABC)-02 study showed that systemic combination chemotherapy of gemcitabine and cisplatin prolonged the survival of patients with inoperable cholangiocarcinoma, making it a treatment standard, and gemcitabine is still the key drug used in chemotherapy of advanced cholangiocarcinoma $(39,40)$. In the present study, we demonstrated that the combination of DZNep and gemcitabine has a synergistic effect on two representative cholangiocarcinoma cell lines, RBE and TFK-1. This synergistic interaction against cell proliferation was associated with a significant increase in apoptosis induction and cell cycle arrest. The combination of gemcitabine and DZNep increased the expression of $\mathrm{p} 16^{\mathrm{INK} 4 \mathrm{a}}$ and $\mathrm{p} 27^{\mathrm{KIPl}}$ when compared with gemcitabine alone, so that the synergistic effect might be partly explained by the significant upregulation of $\mathrm{p} 16^{\mathrm{INK} 4 \mathrm{a}}$ and $\mathrm{p} 27^{\mathrm{KIP} 1}$.

In conclusion, EZH2 inhibitor DZNep appears to be a promising anticancer agent, by attacking key mechanisms involved in the proliferation, cell cycle control and apoptosis of cholangiocarcinoma cells. Moreover, the favorable modulation of $\mathrm{p} 16^{\mathrm{INK} 4 \mathrm{a}}$ and $\mathrm{p} 27^{\mathrm{KIP} 1}$ makes DZNep an optimal candidate for combination therapy with gemcitabine. The synergistic effects observed in the present study may have critical implications for the rational development of innovative regimens consisting of DZNep and gemcitabine to improve the effectiveness of the treatment of cholangiocarcinoma.

\section{References}

1. Alpini G, McGill JM and Larusso NF: The pathobiology of biliary epithelia. Hepatology 35: 1256-1268, 2002.

2. Roberts SK, Ludwig J and Larusso NF: The pathobiology of biliary epithelia. Gastroenterology 112: 269-279, 1997.

3. Welzel TM, Graubard BI, El-Serag HB, et al: Risk factors for intrahepatic and extrahepatic cholangiocarcinoma in the United States: a population-based case-control study. Clin Gastroenterol Hepatol 5: 1221-1228, 2007.

4. Shaib YH, El-Serag HB, Nooka AK, et al: Risk factors for intrahepatic and extrahepatic cholangiocarcinoma: a hospitalbased case-control study. Am J Gastroenterol 102: 1016-1021, 2007.

5. Tao LY, He XD, Qu Q, et al: Risk factors for intrahepatic and extrahepatic cholangiocarcinoma: a case-control study in China. Liver Int 30: 215-221, 2010.

6. Ringrose L and Paro R: Epigenetic regulation of cellular memory by the Polycomb and Trithorax group proteins. Annu Rev Genet 38: 413-443, 2004.

7. Sakamoto Y, Watanabe S, Ichimura T, et al: Overlapping roles of the methylated DNA-binding protein MBD1 and polycomb group proteins in transcriptional repression of HOXA genes and heterochromatin foci formation. J Biol Chem 282: 16391-16400, 2007.

8. Sparmann A and van Lohuizen M: Polycomb silencers control cell fate, development and cancer. Nat Rev Cancer 6: 846-856, 2006.

9. Cao R and Zhang Y: The functions of $\mathrm{E}(\mathrm{Z}) / \mathrm{EZH} 2$-mediated methylation of lysine 27 in histone H3. Curr Opin Genet Dev 14: 155-164, 2004.

10. Simon JA and Lange CA: Roles of the EZH2 histone methyltransferase in cancer epigenetics. Mutat Res 647: 21-29, 2008.

11. Bachmann IM, Halvorsen OJ, Collett K, et al: EZH2 expression is associated with high proliferation rate and aggressive tumor subgroups in cutaneous melanoma and cancers of the endometrium, prostate, and breast. J Clin Oncol 24: 268-273, 2006.

12. Varambally S, Dhanasekaran SM, Zhou M, et al: The polycomb group protein EZH2 is involved in progression of prostate cancer. Nature 419: 624-629, 2002.

13. Kleer CG, Cao Q, Varambally $\mathrm{S}$, et al: $\mathrm{EZH} 2$ is a marker of aggressive breast cancer and promotes neoplastic transformation of breast epithelial cells. Proc Natl Acad Sci USA 100: 11606-11611, 2003.

14. Matsukawa Y, Semba S, Kato H, Ito A, Yanagihara K and Yokozaki H: Expression of the enhancer of zeste homolog 2 is correlated with poor prognosis in human gastric cancer. Cancer Sci 97: 484-491, 2006. 
15. Wagener N, Macher-Goeppinger S, Pritsch M, et al: Enhancer of zeste homolog 2 (EZH2) expression is an independent prognostic factor in renal cell carcinoma. BMC Cancer 10: 524, 2010.

16. Takawa M, Masuda K, Kunizaki M, et al: Validation of the histone methyltransferase EZH2 as a therapeutic target for various types of human cancer and as a prognostic marker. Cancer Sci 102: 1298-1305, 2011.

17. Nakagawa S, Okabe H, Sakamoto Y, et al: Enhancer of zeste homolog $2(\mathrm{EZH} 2)$ promotes progression of cholangiocarcinoma cells by regulating cell cycle and apoptosis. Ann Surg Oncol: Jul 26, 2013 (Epub ahead of print).

18. McCabe MT, Graves AP, Ganji G, et al: Mutation of A677 in histone methyltransferase EZH2 in human B-cell lymphoma promotes hypertrimethylation of histone $\mathrm{H} 3$ on lysine 27 (H3K27). Proc Natl Acad Sci USA 109: 2989-2994, 2012.

19. Karanikolas BD, Figueiredo ML and Wu L: Comprehensive evaluation of the role of EZH2 in the growth, invasion, and aggression of a panel of prostate cancer cell lines. Prostate 70 675-688, 2010

20. Watanabe H, Soejima K, Yasuda H, et al: Deregulation of histone lysine methyltransferases contributes to oncogenic transformation of human bronchoepithelial cells. Cancer Cell Int 8: 15, 2008.

21. Ougolkov AV, Bilim VN and Billadeau DD: Regulation of pancreatic tumor cell proliferation and chemoresistance by the histone methyltransferase enhancer of zeste homologue 2. Clin Cancer Res 14: 6790-6796, 2008.

22. Wagener N, Holland D, Bulkescher J, et al: The enhancer of zeste homolog 2 gene contributes to cell proliferation and apoptosis resistance in renal cell carcinoma cells. Int $\mathbf{J}$ Cancer 123 1545-1550, 2008.

23. Glazer RI, Hartman KD, Knode MC, et al: 3-Deazaneplanocin: a new and potent inhibitor of S-adenosylhomocysteine hydrolase and its effects on human promyelocytic leukemia cell line HL-60. Biochem Biophys Res Commun 135: 688-694, 1986.

24. Tan J, Yang X, Zhuang L, et al: Pharmacologic disruption of Polycomb-repressive complex 2-mediated gene repression selectively induces apoptosis in cancer cells. Genes Dev 21: 1050-1063, 2007.

25. Hayden A, Johnson PW, Packham G and Crabb SJ: S-adenosylhomocysteine hydrolase inhibition by 3-deazaneplanocin A analogues induces anti-cancer effects in breast cancer cell lines and synergy with both histone deacetylase and HER2 inhibition. Breast Cancer Res Treat 127: 109-119, 2011.

26. Miranda TB, Cortez CC, Yoo CB, et al: DZNep is a global histone methylation inhibitor that reactivates developmental genes not silenced by DNA methylation. Mol Cancer Ther 8 : 1579-1588, 2009.
27. Fiskus W, Wang Y, Sreekumar A, et al: Combined epigenetic therapy with the histone methyltransferase EZH2 inhibitor 3-deazaneplanocin A and the histone deacetylase inhibitor panobinostat against human AML cells. Blood 114: 2733-2743, 2009.

28. Jiang X, Tan J, Li J, et al: DACT3 is an epigenetic regulator of Wnt/beta-catenin signaling in colorectal cancer and is a therapeutic target of histone modifications. Cancer Cell 13: 529-541, 2008.

29. Suva ML, Riggi N, Janiszewska M, et al: EZH2 is essential for glioblastoma cancer stem cell maintenance. Cancer Res 69: 9211-9218, 2009.

30. Avan A, Crea F, Paolicchi E, et al: Molecular mechanisms involved in the synergistic interaction of the EZH2 inhibitor 3-deazaneplanocin A with gemcitabine in pancreatic cancer cells. Molecular Cancer Ther 11: 1735-1746, 2012.

31. Xu CR, Cole PA, Meyers DJ, Kormish J, Dent S and Zaret KS: Chromatin 'prepattern' and histone modifiers in a fate choice for liver and pancreas. Science 332: 963-966, 2011.

32. Chang CJ, Yang JY, Xia W, et al: EZH2 promotes expansion of breast tumor initiating cells through activation of RAF1-betacatenin signaling. Cancer Cell 19: 86-100, 2011.

33. Chase A and Cross NC: Aberrations of EZH2 in cancer. Clin Cancer Res 17: 2613-2618, 2011.

34. Toll AD, Dasgupta A, Potoczek M, et al: Implications of enhancer of zeste homologue 2 expression in pancreatic ductal adenocarcinoma. Human Pathol 41: 1205-1209, 2010.

35. Chen Y, Xie D, Yin Li W, et al: RNAi targeting EZH2 inhibits tumor growth and liver metastasis of pancreatic cancer in vivo. Cancer Lett 297: 109-116, 2010.

36. Kikuchi J, Takashina T, Kinoshita I, et al: Epigenetic therapy with 3-deazaneplanocin A, an inhibitor of the histone methyltransferase EZH2, inhibits growth of non-small cell lung cancer cells. Lung Cancer 78: 138-143, 2012.

37. Resnitzky D, Hengst L and Reed SI: Cyclin A-associated kinase activity is rate limiting for entrance into $S$ phase and is negatively regulated in G1 by p27Kip1. Mol Cell Biol 15: 4347-4352, 1995.

38. Girard F, Strausfeld U, Fernandez A and Lamb NJ: Cyclin A is required for the onset of DNA replication in mammalian fibroblasts. Cell 2067: 1169-1179, 1991.

39. Faris JE and Zhu AX: Targeted therapy for biliary tract cancers. J Hepatobiliary Pancreat Sci 19: 326-336, 2012.

40. Thomas MB: Biological characteristics of cancers in the gallbladder and biliary tract and targeted therapy. Crit Rev Oncol Hematol 61: 44-51, 2007. 